vein needed to be divided anyway when we removed the tumor.

Ventilation was ensured by using an armored $8 \mathrm{~F}$ crossfield tracheal cannula through one of the two $1.5-\mathrm{cm}$ access ports. Because cross-field intubation sometimes obstructs the limited visual field through the minithoracotomy, we modified this intubation by forming a loop with the tube. Therefore, strictly speaking, this method is a roundaboutfield intubation rather than a cross-field intubation.

\section{References}

1. Grillo HC, Mathisen DJ. Primary tracheal tumors: treatment and results. Ann Thorac Surg. 1990;49:69-77.

2. Rodriguez E, Pombo F, Aguilera C, Capdevila A. Recurring tracheal leiomyoma presenting as a calcified mediastinal mass. Eur J Radiol. 1996;23:82-4.

3. Gitter R, Daniel TM, Kesser BW, Reibel JF, Tribble CG. Membranous tracheobronchial injury repaired with gastric serosal patch. Ann Thorac Surg. 1999;67:1159-60.

4. Okike N, Payne WS, Cortese DA, Dines DE. Pericardial reconstruction of the membranous trachea after resection of adenoid cystic carcinoma (cylindroma). Mayo Clin Proc. 1978;53:808-10.

5. Crouch RD, Nelson LE, Hawley PC, Frank DA, Williams TE Jr. Onlay patch repair of tracheobronchial rupture. Ann Thorac Surg. 1997;64:1158-60.

\title{
A modified technique of selective lung ventilation through a tracheostomy to facilitate conservative management of iatrogenic tracheal rupture
}

Elizabeth Belcher, MRCP, FRCS, ${ }^{\text {a }}$ Massimo Conti, MD, ${ }^{\mathrm{b}}$ Peter Goldstraw, FRCS, ${ }^{\mathrm{a}}$ and Simon Jordan, FRCS, ${ }^{\mathrm{a}}$

London, United Kingdom, and Lille, France

We describe a modified technique of bilateral bronchial intubation through a tracheostomy to achieve conservative management of iatrogenic tracheal rupture.

\section{CLINICAL SUMMARY}

A 77-year-old woman admitted to the intensive care unit after an out-of hospital respiratory arrest secondary to exacerbation of severe chronic obstructive pulmonary disease underwent a percutaneous dilatational tracheostomy (PCT) using the Ciaglia Blue Rhino (Cook UK Ltd, Letchworth, UK) dilator 5 days post-intubation. Immediately after the procedure, extensive subcutaneous thoracic emphysema and bilateral pneumothoraces developed in the patient. Computed tomography of the chest showed a distal tracheal tear with pneumomediastinum and pneumoperitoneum (Figure 1). The patient was transferred to the Royal Brompton Hospital, for thoracic surgical management. Rigid bronchoscopy revealed a 5-cm longitudinal tear of the posterior wall of the trachea, extending proximally from the level of the carina (Figure 2). Esophageal perforation was excluded by esophagoscopy.

From the Department of Thoracic Surgery, Royal Brompton Hospital, ${ }^{\mathrm{a}}$ London, United Kingdom; and Clinique de Chirurgie Thoracique, CHRU Lille, ${ }^{\mathrm{b}}$ Lille, France.

Received for publication Jan 16, 2008; accepted for publication March 2, 2008.

Address for reprints: Simon Jordan, FRCS, Department of Thoracic Surgery, Royal

Brompton Hospital, Sydney St, London SW3 6NP, United Kingdom (E-mail: s.jordan@rbht.nhs.uk).

J Thorac Cardiovasc Surg 2009; 137:1562-4

$0022-5223 / \$ 36.00$

Copyright (c) 2009 by The American Association for Thoracic Surgery doi:10.1016/j.jtcvs.2008.03.046
Under rigid bronchoscopic control, the airway was decannulated and both main bronchi were selectively intubated with Frova intubation introducers (Cook Critical care, Bloomington, Ind) via the tracheostomy site. Frova introducers of differing colors were used to aid differentiation between right and left main bronchi where endobronchial tubes and introducers impaired visualization of the distal airways. Size 6 armored low-pressure cuffed endobronchial tubes

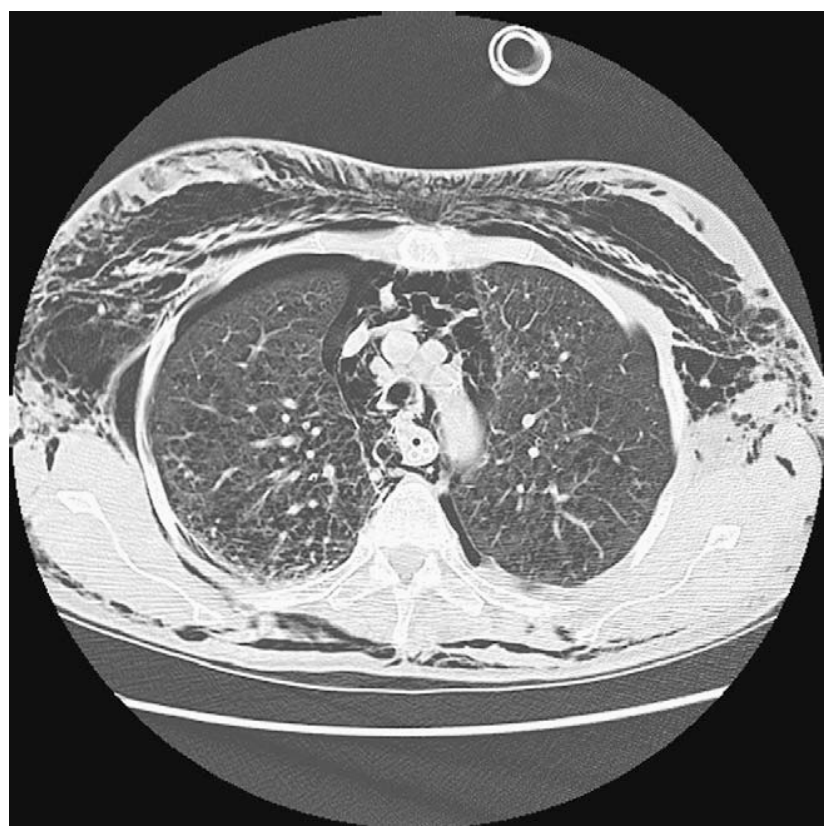

FIGURE 1. Computed tomography scan showing bilateral pneumothoraces and pneumomediastinum secondary to posterior tracheal tear. 


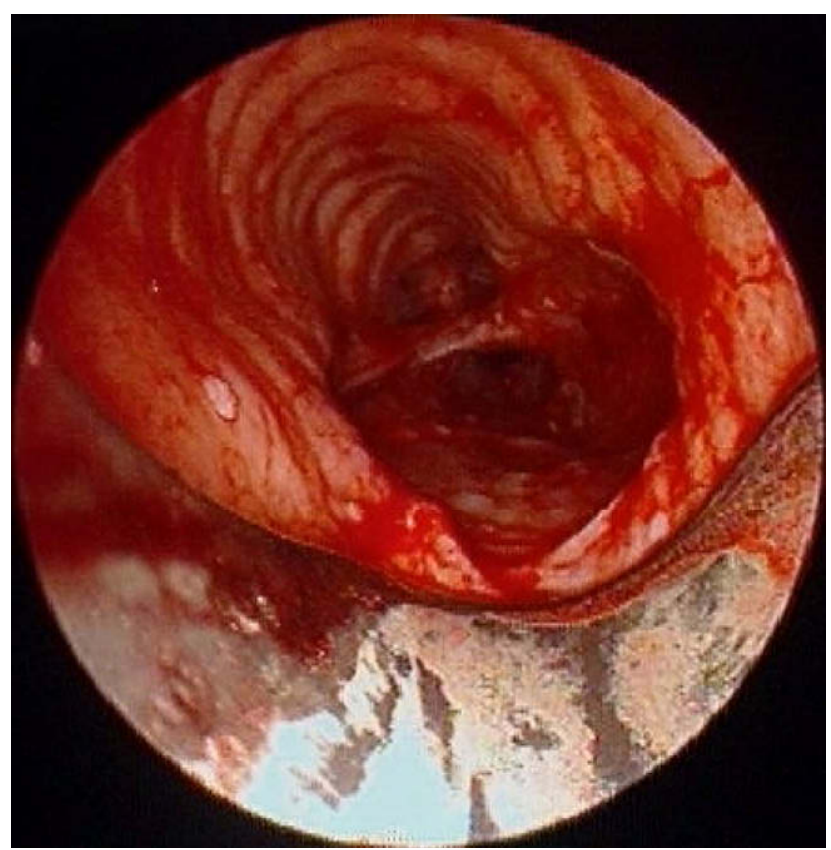

FIGURE 2. View at rigid bronchoscopy showing full-thickness tear of membranous trachea extending proximally from carina to reveal mediastinal structures.

were placed over each Frova introducer to enable guided intubation of both main bronchi. Fiberoptic bronchoscopy was performed through each endobronchial tube to confirm satisfactory placement. Positive pressure ventilation was successfully continued with exclusion of the tear. Examination using rigid bronchoscopy on day 14 post-injury suggested complete healing of the tear by interposition of the esophagus into the laceration. This was confirmed once the endobronchial tubes were removed (Figure 3). Endobronchial tubes were exchanged for an adjustable flange armored endotracheal tube (Bivona, Smiths Medical, London, UK). All interventions were performed in the intensive care unit, without the requirement of transferring the patient to the operating room. The patient was successfully decannulated and discharged from the hospital and remains well 9 months later.

\section{DISCUSSION}

PCT has been increasingly used as an alternative to surgical tracheostomy in critically ill patients. Its use is associated with a lower incidence of wound infection and may reduce clinically relevant bleeding and mortality compared with surgical tracheostomies. ${ }^{1}$ However, iatrogenic tracheal rupture has been recognized as a complication. Bronchoscopic assistance has been recommended while undertaking PCT, but laceration and fistulation into the esophagus remains a recognized complication with its attendant mortality in these already critically ill patients.

Traditionally, surgical management has been the treatment of choice, based on the assumption that mediastinitis

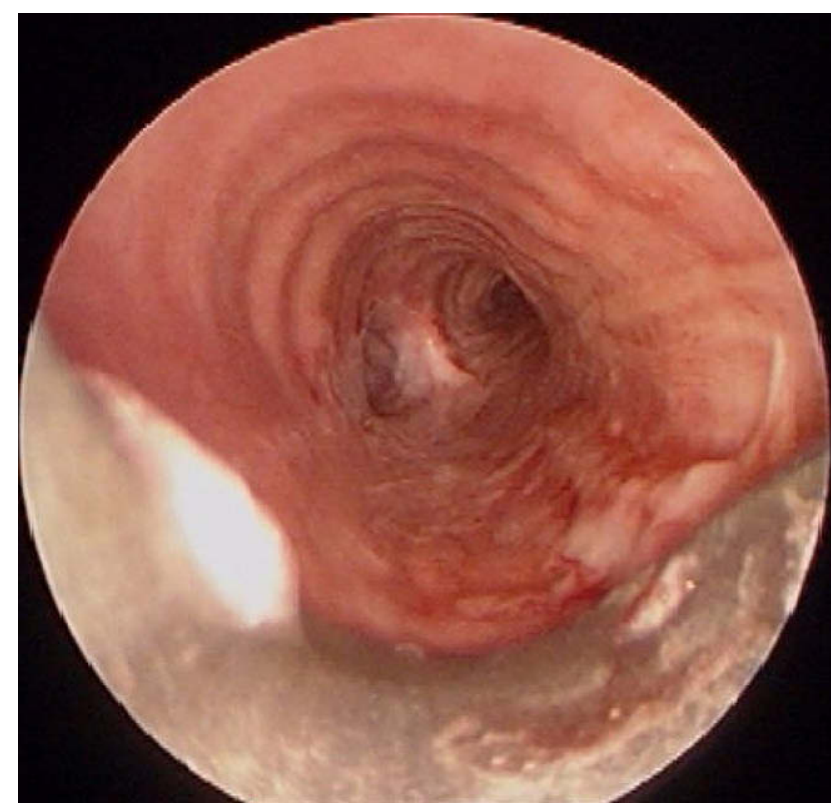

FIGURE 3. Complete healing at site of previous tear in membranous trachea as viewed on day 14 at rigid bronchoscopy.

and tracheal stenosis were obligatory sequelae without such repair. ${ }^{2}$ However, operative mortality in published series is between $13 \%$ and $61 \%{ }^{2,3}$ Initially advocated for patients in whom the operative risk was prohibitively high, a conservative approach, with exclusion of the tracheal tear, has more recently been recommended as the preferred approach for all patients in whom bridging of the lesion is technically possible. ${ }^{4,5}$ For lesions involving the mid third of the trachea alone, simply advancing the tip of the endotracheal tube distal to the tear can restore effective ventilation and allow healing of the tear. However, where lesions involve the distal third of the trachea or proximal main bronchi, a selective bilateral main bronchial intubation with paired endobronchial tubes passed through a tracheostomy has been proposed. ${ }^{5}$ We modified this technique to include the use of rigid bronchoscopy and Frova intubation introducers. Rigid bronchoscopy allows better visualization of the injury and full control of the airway during the bridging procedure. Exchange of the endotracheal tubes is conducted in a controlled fashion without the time constraints of maintaining oxygenation in patients with pre-procedural high $\mathrm{FIO}_{2}$ requirements. Moreover, the superior visualization of the anatomy and pathology afforded by rigid bronchoscopy allows exchange of the endotracheal tubes in such a manner as to reduce the risk of extension of the tracheal injury.

The use of Frova introducers facilitates the passage of the endobronchial tubes into the correct positions. The introducers are easily passed beyond the site of injury and act as "guidewires" for the endobronchial tubes to be correctly positioned within both main bronchi without the risk of extension of the tear because of the inadvertent placement of 
the tracheostomy tubes within the false passage. Introducers of differing colors allow the identification of right and left main bronchial positions even when introducers and endobronchial tubes impair visualization of the distal airways.

We believe the use of rigid bronchoscopy and Frova introducers enables the exchange of endotracheal tubes in a controlled fashion and that superior visualization afforded by this technique minimizes the risk of further iatrogenic injury and therefore successful conservative management.

\section{References}

1. Delaney A, Bagshaw SM, Nalos M. Percutaneous dilatational tracheostomy versus surgical tracheostomy in critically ill patients: a systematic review and meta-analysis. Crit Care. 2006; 10:R55.

2. Gabor S, Renner H, Pinter H, Sankin O, Naier A, Tomaselli F, et al. Indications for surgery in tracheobronchial ruptures. Eur J Cardiothorac Surg. 2001;20:399-404.

3. Meyer M. Iatrogenic tracheobronchial lesions-a report on 13 cases. Thorac Cardiovasc Surg. 2001;49:115-9.

4. Beiderlinden M, Adamzik M, Peters J. Conservative treatment of tracheal injuries. Anesth Analg. 2005;100:210-4.

5. Conti M, Pougeoise M, Wurtz A, Porte H, Fourrier F, Ramon P, et al. Management of postintubation tracheobronchial ruptures. Chest. 2006;130:412-8

\section{Quadruple valve replacement for acute endocarditis}

Joerg Seeburger, MD, Heiner Groesdonk, MD, Michael Andrew Borger, MD, PhD, Denis Merk, MD, Joerg Ender, MD, Volkmar Falk, MD, PhD, Friedrich Wilhelm Mohr, MD, PhD, and Nicolas Doll, MD, PhD, Leipzig, Germany

A 76-year-old man presented with symptoms of heart failure, fever, and fatigue. His medical history included chronic renal and factor XIII insufficiency, diverticulosis, and chronic obstructive pulmonary disease. Transesophageal echocardiography showed endocarditis of the aortic, tricuspid, and pulmonary valves with severe insufficiency (Figure 1), and moderate mitral insufficiency with suspected vegetations (Figure 2).

Cardiac catheterization was normal. Broad-spectrum antibiotic coverage was initiated with ampicillin, gentamycin, and imipenem. After 10 days of conservative therapy, the patient underwent surgery because of ongoing symptoms of heart failure.

A median sternotomy and standard cannulation were performed. Moderate hypothermia and antegrade blood cardioplegia were administered. Because of large vegetations $(>1$ $\mathrm{cm}$ ) on all 4 valves, no reconstructive surgery was possible. The mitral valve was replaced (31-mm Epic, St Jude Medical, Minneapolis, Minn), followed by the tricuspid valve (33-mm Epic), the pulmonary valve (27-mm Freestyle, Medtronic Inc, Minneapolis, Minn), and the aortic valve (23-mm Epic). Because of third-degree arteriovenous block, a pacemaker lead (Medtronic Kappa) was attached epimyocardially and tunneled under the costal margin. The intraoperative course was otherwise uneventful, and the patient was weaned from cardiopulmonary bypass with small doses of inotropes.

From the Heartcenter Leipzig, Leipzig University, Leipzig, Germany.

Received for publication Jan 16, 2008; revisions received Jan 16, 2008; accepted for publication Feb 7, 2008.

Address for reprints: Joerg Seeburger, MD, Heartcenter Leipzig-University, Struempelstrasse 3904289 Leipzig, Germany (E-mail: j.seeburger@web.de).

J Thorac Cardiovasc Surg 2009; 137:1564-5

$0022-5223 / \$ 36.00$

Copyright (c) 2009 by The American Association for Thoracic Surgery doi:10.1016/j.jtcvs.2008.02.078
Postoperative bleeding required blood transfusion, coagulation factors, and recombinant activated factor VII.

Blood and aortic valve cultures revealed Enterococcus faecalis and Gemella morbillorum. Postoperative treatment was prolonged because of intracerebral bleeding with resultant left-sided hemiplegia, persistent upper gastrointestinal bleeding resulting in a Billroth II operation, and hemodialysis. Predischarge echocardiography showed excellent function of all 4 prosthetic valves. At 3 months follow-up, the patient is in rehabilitation and generally good health with gradually resolving neurologic symptoms.

\section{COMMENT}

Heart valve replacement for endocarditis is a relatively common operation, but the current case is notable for 2 reasons: (1) Endocarditis was caused by simultaneous infection

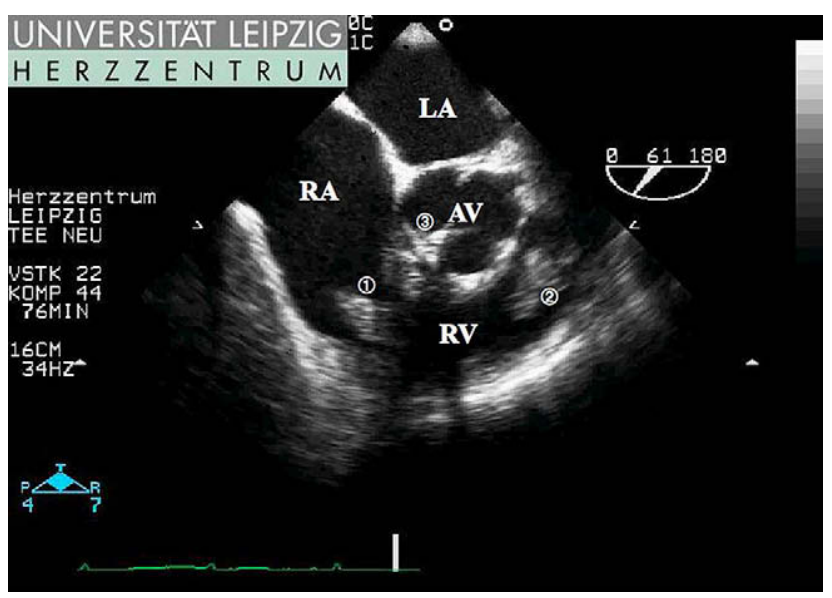

FIGURE 1. Transesophageal echocardiography showing severe endocarditis of the tricuspid (1), pulmonary (2), and aortic (3) valves. $L A$, Left atrium; $R A$, right atrium; $A V$, aortic valve; $R V$, right ventricle. 